\title{
Monetizing Car Data: A Literature Review on Data-Driven Business Models in the Connected Car Domain
}

\author{
Felix Sterk \\ Karlsruhe Institute of Technology \\ felix.sterk@kit.edu
}

\author{
David Dann \\ Karlsruhe Institute of Technology \\ david.dann@kit.edu
}

\author{
Christof Weinhardt \\ Karlsruhe Institute of Technology \\ christof.weinhardt@kit.edu
}

\begin{abstract}
The amount of data generated by a single modern vehicle is exploding. Consequently, the entire global automotive industry is facing the question of how to monetize this valuable data. Triggered by the connectivity trend, data-driven business models disrupt the automotive ecosystem by changing mobility behavior, proliferation of technical enablers, new strategic collaborations, and shifting revenue streams. In this study, we analyze the existing body of literature on data-driven business models in the connected car domain and structure it according to four dimensions-value proposition, value architecture, value network, and value finance. Thereby, we contribute to the business model research by providing a comprehensive overview and categorization of existing works in this area and laying the foundation for future research.
\end{abstract}

\section{Introduction}

Connectivity is a major trend in the global automotive industry, transforming modern vehicles into highly intelligent computers on wheels [1, 2]. Equipped with multi-layered sensor technology, they already capture and share a tremendously growing amount of data, including geolocation, fuel consumption, vehicle performance, and driver condition [3, 4, 5]. Even today, a connected vehicle generates $25 \mathrm{~GB}$ of data per hour, whereby big data and analytics become new sources of value creation [6]. As of 2030, McKinsey \& Company expects the annual incremental value from car data monetization to reach $\$ 250$ billion to $\$ 400$ billion [7]. However, original equipment manufacturers (OEMs) are still struggling with connectivity, so few are realizing the immense potential of connected cars, and even fewer are fully monetizing their car data $[3,7,8]$.

Although researchers are investigating big data for years, they have scarcely touched on selling and monetizing data assets directly [9]. However, while the digital transformation and the embrace of data-driven business models (DDBMs) rather marginally concerned the automotive industry in the past, these areas are increasingly gaining relevance, both in research and practice. While OEMs are launching digital services such as BMW ConnectedDrive and Mercedes me connect, they are threatened by major tech companies such as Google, introducing its own car operating system Android Automotive, or Apple, even planning its rumored electric car [10]. At the same time, several scholars work on related topics, such as novel connected services $[8,11]$, required collaboration $[12$, 13], technological enablers [14, 15], or shifting revenue pools [16, 17]. As our society is strongly driven by mobility, Kaiser et al. state that "[...] it is almost our duty to examine the emergence of digital services based on vehicle usage data more closely" [18, p.40].

Against this backdrop, we follow Kaiser et al.'s plea by focusing on better understanding business models with the potential to create and capture value from the data collected by modern vehicles. More specifically, we raise the following research question: What is the state of the art in research covering data-driven business models in the connected car domain? We approach this question by conducting a structured review of the literature with the aim to discover common approaches, insights, and research foci and-building on this-identify existing gaps and derive opportunities for future research attention. Therefore, we classify the identified body of literature regarding the business model framework proposed by Al-Debei and Avison [19] and extend their concept to the context of connected cars. To the best of our knowledge, this work represents the first structured literature review on this topic, closing a research gap in itself.

\section{Methodology}

Selection of Papers: Our literature search and selection process follow the methodological suggestions by Webster and Watson [20] and vom Brocke et al. 
[21]. Following the classification by Paré and colleagues [22], the overreaching goal of our research synthesis is explanation building and belongs to the category of theoretical reviews. As the existing literature on DDBMs and connected cars is highly interdisciplinary, we queried several databases (i.e., AIS Electronic Library, Emerald Insight, IEEEXplore Digital Library, ProQuest, ScienceDirect/Scopus, Web of Science) for matching our search query ${ }^{1}$ in title, abstract, or keywords. We obtained a total of 787 studies (Figure 1). After removing duplicates, this yielded 547 articles for further review. We then analyzed each article's title and abstract, resulting in 94 articles, and, subsequently, reviewed all full texts. Finally, we excluded articles that do not explicitly fit within the scope of our literature review, applying four inclusion criteria: (1) the study must examine at least one business model dimension, (2) the study must focus on the connected car domain, (3) the paper must be available in English, and (4) only peer-reviewed papers were considered. This resulted in a set of 29 relevant articles. Subsequent forward and backward search with this set of relevant papers yielded 16 additional relevant articles, resulting in a total of 45 papers for in-depth review.

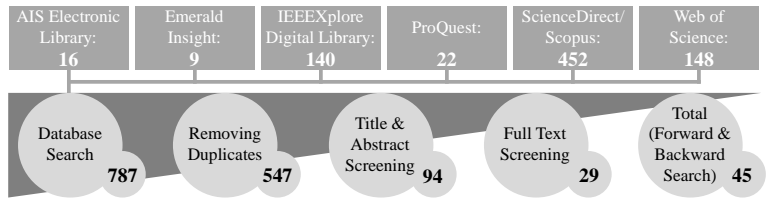

Figure 1. Literature search process

Classification Procedure: The literature review follows a concept-centric approach [20]. Initially, we examined the identified articles for business model dimensions using the business model framework proposed by Al-Debei and Avison [19]. The framework fits our review endeavor for two reasons. First, it is one of the few business model frameworks developed particularly for digital business models. Second, this framework captures the multidimensionality of business models, including the essential dimensions from previous conceptualizations. The framework contains the four dimensions of value proposition, value architecture, value network, and value finance. The authors outline the four dimensions as follows. Value proposition deals with products and services that are offered to satisfy customer needs. Value architecture includes the organization's technological architecture and organizational infrastructure. Value network describes the coordination and collaboration

\footnotetext{
1 "business model*" AND (connected OR data* OR digital*) AND (car* OR vehicle* OR automotive*)
}

among parties and multiple companies, and value finance concerns information related to costing, pricing, and revenue breakdown.

Since the four dimensions according to Al-Debei and Avison [19] are relatively general, we need a more refined classification, specifically for the connected car context. Consequently, in a second step, we derive key concepts for paper categorization based on their business model framework. Following the suggestions of vom Brocke et al. [21], we screened an initial set of papers stemming from recent peer-reviewed conference proceedings and journal papers, as we assumed that these papers well reflect the contemporary state of literature. Next, the author team independently identified a set of concepts for classification. The subsequent discussion of all identified concepts resulted in the following breakdown of the business model dimensions: value proposition (i.e., safety, convenience, cost reduction, traffic efficiency, infotainment), value architecture (i.e., resources, capabilities), value network (i.e., actors \& roles, strategic partnerships), and value finance (i.e., revenue streams, cost structure). Note that our categorization is not disjunctive and each publication may be assigned to more than one category. Table 1 summarizes the reviewed papers and specifies the assigned concepts. All reviewed articles have been published within the last six years: 2021 (2), 2020 (7), 2019 (5), 2018 (6), 2017 (10), 2016 (8), and 2015 (7).

\section{Results}

With the rise of vehicle connectivity, the amount of data from vehicles will grow exponentially [4], receiving a considerable amount of research attention [8]. To provide some structure and overview, we use the derived characteristics to discuss, summarize, and synthesize the identified publications. First, we take a look at value propositions for individual drivers and fleet managers, which fall into five broad categories (i.e., safety, convenience, cost reduction, traffic efficiency, and infotainment). Next, we focus on data and associated infrastructure as enabling resources for monetizing car data. In addition, we address the challenge of many incumbents to develop specific capabilities either internally or externally. We then examine actors in the connected car ecosystem, that will naturally be forced to take on certain roles (e.g., service providers or platform providers) and enter into strategic partnerships with multiple entities [51, 13, 31]. Last, we elaborate on financial aspects around connected car business models, including their revenue streams and cost structure. 
Table 1. Classification of literature on DDBMs in the connected car domain

\begin{tabular}{|c|c|c|c|c|c|c|c|c|c|c|c|}
\hline \multirow[b]{3}{*}{ Source } & \multicolumn{11}{|c|}{ Business Model Dimension } \\
\hline & \multicolumn{5}{|c|}{ Value Proposition } & \multicolumn{2}{|c|}{\begin{tabular}{|c|c} 
Value \\
Architect.
\end{tabular}} & \multicolumn{2}{|c|}{\begin{tabular}{|c|} 
Value \\
Network
\end{tabular}} & \multicolumn{2}{|c|}{\begin{tabular}{|c|} 
Value \\
Finance
\end{tabular}} \\
\hline & 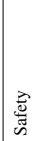 & 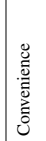 & 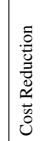 & 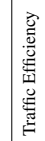 & 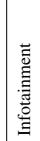 & 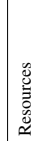 & 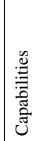 & 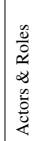 & 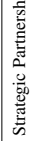 & 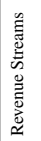 & 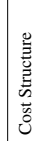 \\
\hline Andersson \& Mattsson [23] & $x$ & $x$ & $x$ & & $x$ & & & & & & \\
\hline 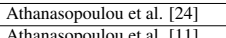 & $x$ & & $x$ & & & & & & & $x$ & $\times$ \\
\hline $\begin{array}{l}\text { Athanasopoulou et al. [11] } \\
\text { Bauer et al. [25] }\end{array}$ & $x$ & $x$ & & $x$ & $x$ & $x$ & $x$ & & & & \\
\hline Bosler et al. [10] & $x$ & $x$ & & $x$ & $x$ & $x$ & & $x$ & $x$ & & \\
\hline Brandt and Ahlemann [26] & $x$ & & & $x$ & $x$ & $x$ & $x$ & & $x$ & & \\
\hline Bregandt et al. [27] & & & & & $x$ & & & & & & \\
\hline Chanias \& Hess [28] & & & & & & & $x$ & & & & \\
\hline Conrad & $x$ & $x$ & $\times$ & & & & & & & & \\
\hline Coppola \& Morisio [15] & $x$ & $x$ & $x$ & $\times$ & $\times$ & $x$ & & & & & \\
\hline De [30] & $x$ & $x$ & $x$ & $x$ & $x$ & $x$ & & $x$ & $x$ & $x$ & $\times$ \\
\hline Grieger \& Ludwig & $x$ & & & $x$ & & & $x$ & $x$ & $x$ & & \\
\hline Hanelt et al. [32] & $x$ & $x$ & & & $x$ & & $x$ & $x$ & & $x$ & \\
\hline Kaiser et al. [33] & $x$ & & $x$ & & $x$ & $x$ & & $x$ & & & \\
\hline Kaiser et al. [34] & $x$ & $x$ & $x$ & $x$ & $x$ & $x$ & & $x$ & $x$ & & \\
\hline Kaiser et al. [2] & $x$ & & $x$ & & $x$ & $x$ & & $x$ & & $x$ & \\
\hline $\begin{array}{l}\text { Kaisere et al. }[12] \\
\text { Kaiser et al. }[18]\end{array}$ & $x$ & & $x$ & & & $x$ & & $\frac{x}{x}$ & $x$ & & \\
\hline K Kaiser & $\mid x$ & & $x$ & $x$ & & $x$ & $x$ & $x$ & $x$ & & \\
\hline Kukk: & $x$ & & & & & & & $x$ & $\times$ & $x$ & $x$ \\
\hline Llopis- & $x$ & & & & $x$ & & & & & & $x$ \\
\hline Marat & $x$ & $x$ & $x$ & & & $x$ & & & & & \\
\hline Martens \& Müller-Langer [14] & $x$ & 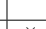 & $x$ & & $x$ & $x$ & 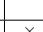 & $\frac{x}{x}$ & 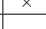 & \begin{tabular}{|l}
$x$ \\
$x$ \\
$x$
\end{tabular} & \\
\hline $\begin{array}{l}\text { Mikusz \& Herter [1]] } \\
\text { Mikusz et al. [39] }\end{array}$ & $\frac{x}{x}$ & $\frac{x}{x}$ & $\frac{x}{x}$ & $\frac{x}{x}$ & & $x$ & $x$ & $\frac{x}{x}$ & & \begin{tabular}{|c|c|c|}
$x$ \\
$x$
\end{tabular} & \\
\hline $\mathrm{Mil}$ & $\bar{x}$ & $x$ & $x$ & $\bar{x}$ & & & $x$ & & & & $x$ \\
\hline & & $x$ & & & $x$ & & $x$ & & & & \\
\hline Nisc & & & & & $x$ & & & $x$ & $x$ & & \\
\hline & $\times$ & & $x$ & & & $x$ & & & & & \\
\hline $\begin{array}{l}\text { Piccini } \\
\text { Pitit et }\end{array}$ & $x$ & & $x$ & & $\times$ & $x$ & \begin{tabular}{|l|}
$\times$ \\
\end{tabular} & x & \begin{tabular}{|c|c|}
$x$ \\
$x$
\end{tabular} & & \\
\hline yoni[45] & $x$ & & & & $x$ & $x$ & & $x$ & $x$ & & \\
\hline & & & & & & & & $\bar{x}$ & & & \\
\hline & & & $x$ & & & & & $\bar{x}$ & & & \\
\hline $\mathrm{Ri}$ & & $x$ & & & $x$ & & $x$ & $x$ & $x$ & & \\
\hline & & & $x$ & & & $x$ & & & & & \\
\hline & $\frac{x}{x}$ & & $x$ & & $x$ & $\frac{x}{x}$ & & 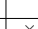 & & & \\
\hline$\frac{S t}{S v}$ & & $\frac{1}{x}$ & & & & $\hat{x}$ & $x$ & & & & \\
\hline [51] & & $x$ & & & 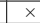 & & $x$ & & $x$ & $x$ & \\
\hline & $\frac{x}{x}$ & $x$ & $x$ & $\frac{x}{x}$ & $x$ & $x$ & & & & & \\
\hline & & & & & & & $x$ & & & & $x$ \\
\hline & $x$ & $x$ & $x$ & $x$ & & & & & & & \\
\hline & & & $x$ & $x$ & & & & & & & \\
\hline Zhao et al. [13] & 29 & 19 & 24 & 14 & 22 & 21 & 14 & 22 & 16 & 9 & 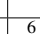 \\
\hline
\end{tabular}

\subsection{DDBM Dimension 1: Value Proposition}

Ongoing digitalization and connectivity virtually force automotive companies to change their business models from a goods-dominant towards a service-dominant logic [31, 32, 12, 48, 34]. However, no matter which services car data makes possible, monetizing them is not feasible if customers do not see their benefits [43, 28]. Accordingly, various scholars highlighted affected services and their primary value propositions to customers. Specifically, we identified in total 38 different connected car services in the literature corpus that may generate added value for private car owners and fleet managers (Table 2) in terms of one or more aspects:

Safety: Connected car data enables a broad range of services to increase vehicle and traffic safety. In this regard, various authors highlight driving style detection as a means to encourage safer and eco-efficient driving behavior $[4,10,18,30]$. In addition, automated pothole detection could generate cost-efficient maintenance measures of road conditions, which might attract the interest of city planners as further stakeholders [8, 2]. Another safety-enhancing service, which was most frequently mentioned is the intelligent emergency call (eCall) (e.g., [14, 11, 44]). In case of an accident, the eCall system automatically contacts an emergency call-center and communicates the vehicle position, including relevant data (e.g., time of the accident, vehicle type).

Convenience: Beyond traffic safety, car data can also improve the overall experience of driving and vehicle usage. BMW, for instance, offers remote services for (un-)locking vehicles, indicating the vehicle's location within an app or activating the vehicle's climate control remotely [34]. The service tested by Volvo in 2014 goes even one step further, using the remote keyless entry for digital food delivery into the car $[51,23,50]$. This car delivery concept is an example of capitalizing on a continuously changing product, increasing variety, and enabling multi-sided platform solutions to mediate economic transactions [50]. Besides remote services, convenience can be enhanced by concierge services, where the driver gets connected to call-center agents to find and book nearby services (e.g., hotel booking), with addresses sent directly to the navigation system [34, 16].

Cost Reduction: Another customer value enabled by the increased use of car data are monetary benefits stemming from, for instance, optimized fuel consumption, automated payment schemes on road tolls, or usage-based insurance (UBI) [8, 30]. Reviewing existing research shows that the latter, involving data-based pricing models adapted towards users' driving behavior, is the most widespread and intensively studied connected car service hitherto [44, 49, 38, 42, 29]. In this regard, Pütz et al. [44] show that insurance companies have to adapt their digital service offerings in light of vehicle ownership changing from many individuals to fewer commercial fleet providers. In addition, Roth et al. [49] investigate privacy issues in UBI models. They observe the necessity for a transparent UBI model that is comprehensible and controllable for users, including thorough data protection.

Traffic Efficiency: Location-based services enable a wide range of smart navigation use cases. Applications such as dynamic routing, real-time traffic information, and parking assistance help reducing users' travel time $[15,30,17]$. One example of this is the Google Maps app. Users share personal data via their smartphones while, at the same time, using other users' 
aggregated real-time traffic information for navigation [48]. Analyzing users' evaluation of smart navigation's value proposition, Mikusz and Herter [39] distinguish between three service components: (i) customization, including a fully interactive screen, (ii) situational services, enabling reservation of parking spaces or charging stations, and (iii) data co-creation, realizing accurate predictions of traffic congestion. Using conjoint analysis, they show that the customization feature is most valued.

Infotainment: According to Hanelt et al. [32], preferences are shifting from the pure driving experience or technical performance features to aspects such as information and entertainment (i.e., infotainment), whereby the vehicle itself may change its role from a status symbol to a device for digital experiences. To achieve this, OEMs seek to improve end-user experience with digital technologies $[51,2]$ such as augmented reality [53] and human-machine interfaces (HMI) enabling seamless infotainment [43]. Infotainment systems in modern vehicles already contain numerous applications, including music and video streaming, internet access via an in-car hot spot, or in-car smartphone integration [4, 30, 15]. Examples for the latter are third-party offerings such as Google Android Auto and Apple CarPlay, enabling the driver to use smartphone apps within the car's head unit [10].

\subsection{DDBM Dimension 2: Value Architecture}

Besides servitization and digital transformation of their value proposition, businesses face the required evolution of their structural design, including its technological architecture and organizational infrastructure that allows the provision of connected services $[19,24]$. We describe this stream of research along the required resources and capabilities that existing actors want and need to acquire.

Resources: Enabling resources for the monetization of connected car data refers to the data itself as well as infrastructural technologies inside and outside the vehicle, including high-performance computing, in-car HMI, 5G data towers, and data platforms [12]. Regarding these resources, we identified three prevalent themes in the literature:

(1) Data Categories: Soley et al. [4] provide a general overview of the data categories relevant for connected car services and the monetary value assigned to them by different actors. In line with other scholars (e.g., $[15,10,39,42,52]$ ), they distinguish between personally identifiable information data generated outside the vehicle by the drivers (e.g., phone numbers or login data), geolocation data
Table 2. Overview of distinct connected car services

\begin{tabular}{|c|c|c|c|}
\hline $\begin{array}{l}\text { Value } \\
\text { Prop. }\end{array}$ & Connected Car Service & Source & $\sum$ \\
\hline \multirow{9}{*}{ 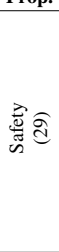 } & Emergency Call (eCall) & $\begin{array}{l}{[32,34,30,10,16,39,17,38,11,} \\
24,15,52,14,44,36]\end{array}$ & 15 \\
\hline & Breakdown Call (bCall) & {$[30,10,16,38,15,45,8]$} & 7 \\
\hline & Remote Diagnostics & {$[23,45,30,17,16,14,24,31,4]$} & 9 \\
\hline & Predictive Maintenance & {$[23,37,26,8]$} & 4 \\
\hline & Service Reminder & {$[30,33,34,8]$} & 4 \\
\hline & Stolen Vehicle Recovery & {$[34,52,30,15,42,38,54]$} & 7 \\
\hline & Road Condition Monitoring & {$[30,4,10,18,15]$} & 5 \\
\hline & Driver Fatigue Detection & {$[11,52,15]$} & 3 \\
\hline & Driving Style Suggestions & {$[18,2,29,8,39,33,35]$} & 7 \\
\hline \multirow{8}{*}{ 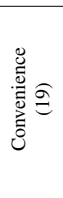 } & Concierge Services & {$[8,48,16,34]$} & 4 \\
\hline & Over-The-Air (OTA) Updates & {$[10,30,23,11]$} & 4 \\
\hline & Electronic Driver Logbook & {$[29,8]$} & 2 \\
\hline & In-Car Delivery & {$[23,17,51,50]$} & 4 \\
\hline & Connected Service Booking & {$[23,30,52]$} & 3 \\
\hline & Remote Services (e.g., door (un)lock) & {$[30,34,16,39,17,10,40,54,11]$} & 9 \\
\hline & Hands-Free Messaging & {$[11,15,30,32,54]$} & 5 \\
\hline & Parked Vehicle Locator & {$[34,30,38,10]$} & 4 \\
\hline \multirow{8}{*}{ 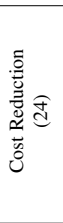 } & Usage-Based Insurance (UBI) & $\begin{array}{l}{[11,29,15,33,2,30,38,16,17,42,} \\
49,54,44,47,8,14,35]\end{array}$ & 17 \\
\hline & Platooning & {$[55]$} & 1 \\
\hline & Fleet Management Solutions & {$[33,8,23,14,29,11,18]$} & 7 \\
\hline & Algorithm-Based Vehicle Pricing & [15] & 1 \\
\hline & Automated Payment Schemes & {$[30,52,4]$} & 3 \\
\hline & In-Vehicle Purchase \& Payment & {$[30,11]$} & 2 \\
\hline & Location-Based Advertisement & {$[15,30,24,47]$} & 4 \\
\hline & Eco Driving (e.g., fuel saving) & {$[15,39,30,34,8,11]$} & 6 \\
\hline \multirow{6}{*}{ 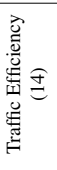 } & Dynamic Routing & {$[16,39,17,30,34,35]$} & 6 \\
\hline & Real-Time Traffic Information & {$[15,39,17,34,10,30,11]$} & 7 \\
\hline & Real-Time Parking Assistance & $\begin{array}{l}{[11,26,34,30,52,39,54,55,15 \text {, }} \\
31]\end{array}$ & 10 \\
\hline & Geofencing & {$[30,34]$} & 2 \\
\hline & "Points of Interest"-Search & {$[39,30]$} & 2 \\
\hline & Location Air Pollution Data & [30] & 1 \\
\hline \multirow{7}{*}{ 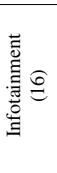 } & Music Video Streaming & {$[10,15,30,4,52]$} & 5 \\
\hline & Smartphone Integration & {$[23,11,10,45,15,14,34]$} & 7 \\
\hline & Social Network Integration & {$[30,11,15]$} & 3 \\
\hline & Wifi-Hotspot & {$[4,11,15,30,40]$} & 5 \\
\hline & News, Weather, FM Radio & {$[10,30,15,26]$} & 4 \\
\hline & Vehicle Status (e.g., fuel level) & {$[32,34,32,48,10,30]$} & 6 \\
\hline & Gamification & {$[34,33,8]$} & 3 \\
\hline
\end{tabular}

generated either by the vehicles or by peripheral devices (e.g., smartphone), application data generated by smartphones or infotainment systems (e.g., music streaming), and vehicle-specific data generated by and for vehicles themselves (e.g., sensor or performance data). Surprisingly, Soley et al. [4] reveal that connected car data has a higher monetary value than businesses and individuals assumed, which is why they recommend securing this data and establishing comprehensive rules pertaining to data ownership and management.

(2) Data Access: While OEMs have exclusive access to the data a car generates [12, 14, 33], independent service providers have to identify other ways to capture this data. Martens and Mueller-Langer [14] explored four alternative technical gateways that could offer independent service providers similar data access options. First, the on-board diagnostics (OBD) port establishes a technical standard for data access. Drivers can plug a dongle into the OBD port to allow remote access to the vehicle data (e.g., [4, 15, 44]). The data is transmitted via USB or mobile network to the driver's smartphone or directly to an external service provider. Second, the central server, controlled by OEMs, collects data directly from the car internal data network. This monopoly for OEMs led to discussions 
on a neutral server, where data storage, processing, and customer interaction with service providers are handled by a third-party platform (e.g., Caruso). However, transmitting data from the central server to a third-party server requires driver's consent [15, 14]. Third, on-board platforms are in-car operating systems on which service providers can install their application software to extract data and run services for the driver, comparable to a smartphone operating system [14]. Last, consumer media platforms enable users to seamlessly integrate their favorite smartphone operating systems such as Apple iOS and Google Android into cars (e.g., [15, 10, 45]). Eventually, all four gateways suffer from shortcomings in data portability, switching costs, and network effects, as well as economies of scale and scope in data analytics [14].

(3) Data Sharing: In addition to the technical requirements necessary for monetizing car data, we examined the articles in terms of incentives and measures encouraging stakeholders to share their car data. Fundamental approaches regarding this issue are monetary incentives (e.g., price discounts on existing services) and non-monetary incentives (e.g., novel services only feasible by data sharing) [26]. In addition, Brandt and Ahlemann [26] consider including data collection in the employment contract of professional drivers. Besides that, other studies suggest that privacy concerns have to be mastered to support the emergence of connected services with enough data $[4,8]$. Accordingly, it is vital to process data in an anonymized form or increase trust in the other party by being transparent about what kind of data cars generate, process, store, and transmit [15, 49]. Last, several authors point out that customers are willing to share personal and vehicle data if they see a direct benefit from connected services for themselves [4, 8, 26, 39]. Thus, companies need to provide a clear and compelling value proposition to customers to encourage data sharing (e.g., innovative products, driving recommendations, or gamification aspects).

Capabilities: In the face of ongoing digitalization and increasing connectivity, it comes to no surprise that incumbents such as traditional OEMs are struggling to build the specific capabilities they need, either internally or externally (e.g., [28, 53, 40, 24]). However, we found four approaches to obtain these required competencies. The first is hiring new talents with technological skills such as app programming or big data analytics [43, 31, 32]. Next is the implementation of startup mentality (e.g., be agile, trial and error) [43] by founding internal startups or labs [26] to foster creativity and allow their employees to propose and experiment with new ideas. A prime example of this is Volvo Cars, which set up an innovation hub in 2010. However, in their interview study, Svahn and colleagues $[50,51]$ observed that Volvo could not realize their connected car vision through an external subsidiary due to the potential risk of turning into a rival organization. Besides these two internal approaches, there are open innovation hackathons [16, 17, 26] and external partnerships [51, $48,26]$ to capture the skills needed.

\subsection{DDBM Dimension 3: Value Network}

Next, we take a closer look at existing actors and roles in the field of connected car ecosystems, as well as how stakeholders within a value network may achieve win-win situations by forming strategic partnerships.

Actors \& Roles: Existing literature lists a variety of different stakeholders operating in the connected car ecosystem. Following Al-Debei and Avison [19], we distinguish between the actors of which a connected car ecosystem is composed and the roles played by these actors. The group of actors capturing the car data monetization opportunity primarily consists of drivers, OEMs, suppliers, startups, tech companies, fleet operators, workshops, infrastructure players, retailers, insurers, roadside assistance, and governments (e.g., $[13,45,48])$. One of the first decisions for these actors is what role to play in the connected car ecosystem. Stocker et al.'s [8] classification distinguishes between four distinct roles:

(1) Primary End-Users are individual customers (e.g., drivers) who directly benefit from connected services based on their shared car data [8]. Hence, the user is not a passive actor but an active integrator of resources and, thereby, value co-creator [39, 48]. This co-creation of value is an integral aspect in the realization of a consumer-centric service portfolio [31]. One example of this is sharing personal data via smartphone with Google Maps while using other drivers' aggregated real-time traffic information for navigation [48]. Besides data co-creation, OEMs may involve their customers in the product design processes through digital interaction to rapidly sense and respond to changing customer needs [32].

(2) Secondary End-Users are organizational customers who indirectly benefit through collected and assessed car data from multiple vehicles by consuming connected services [8]. For instance, road traffic departments can make informed decisions based on traffic data to increase road safety and reduce driving emissions [33], or city planners may use road condition data for maintenance and repair [2, 8]. Besides, organizational customers such as driving schools may be assisted in supervising students based on driving 
style monitoring, teaching them to drive safer and economically [33].

(3) Service Providers are organizations who provide connected services for various end-users, thereby monetizing car data [8]. Obviously, OEMs are seeking to exploit their supremacy position with exclusive data access to develop data-based solutions such as mobility services, on-demand services, or infotainment services [36]. However, other ecosystem actors also slip into the service provider's role. Bosch, for instance, as a supplier for emergency call management [16], or various insurers capitalizing on car data by offering usage-based insurance contracts [29, 38, 42, 49]. Moreover, a large number of startups entered the ecosystem, creating numerous digital services based on car data from the OBD interface or the driver's smartphone. An example is Zendrive.com, providing smartphone-powered and gamified driving analytics [13, 33, 34].

(4) Platform Providers operate the required infrastructure for the connected car ecosystem and allow service providers to establish their data-based services and end-users to consume them in return for their car data [8]. Bosler et al. [10] identified three alternative platform concepts which currently dominate connected car ecosystems. First, OEM platforms offering customers additional services inside and outside vehicles (e.g., BMW ConnectedDrive, Mercedes me connect). Next, platforms for smartphone integration enabling drivers to use their smartphones and related apps via the built-in head unit (e.g., Google Android Auto and Apple CarPlay). Last, "Platforms as a Service"-approaches for connected cars offered by third-party providers. These providers operate individual platform concepts to deliver services across the OEM to the end-user and provide an alternative to self-development.

Strategic Partnerships: In the fast-evolving connected car environment, companies cannot succeed independently [13]. Thus, the collaboration between multiple actors within the ecosystem is necessary to capture the full value from vehicle data for several reasons. First, strategic partnerships enable companies to maximize their value proposition by operating complex services that they can not realize on their own, such as usage-based insurance models or predictive maintenance approaches [44, 31, 36]. Furthermore, collaborations facilitate the acquisition of external knowledge and new competencies [48, 51, 26] and allow access to new revenue sources [30, 51, 45]. While OEMs have incentives to partner with platforms to benefit from the additional data sales [14], platform providers are expecting increasing platform growth through network effects [10]. Service providers, in turn, benefit from the data access options offered by these platforms [14]. Due to the importance of close strategic partnerships, automotive companies must place the same importance on these ecosystem partners as they do on vehicle owners [30]. In addition to the brand-dependent business approaches that have been most dominant so far, Kaiser et al. [34] identified two collaborative approaches to provide connected services. First, there are brand-independent services (e.g., driving behavior analytics) where several organizations use the driving data. Second, strategic alliances being formed between OEMs and technology companies (e.g., BMW, IBM) to establish DDBMs. However, according to Piccinini et al. [43], on the one hand, cooperation between different actors is necessary to deliver digital products via standardized platforms. On the other hand, however, the same digital players will also become competitors concerning future mobility.

\subsection{DDBM Dimension 4: Value Finance}

Finally, this stream focuses on how players in the connected car ecosystem generate revenue from their DDBMs and what costs are incurred in operating them. More specifically, we refer to the elements revenue streams and cost structures.

Revenue Streams: Once automotive companies have collected or acquired the connected car data, they seek to monetize them [14]. This may be achieved following two different approaches:

(1) Selling Services: Creating novel data-based services leads to new business opportunities and new revenue streams [2, 51, 23, 24]. These include the currently emerging subscription-based services that were most frequently mentioned in our literature corpus (e.g., BMW ConnectedDrive [36], Audi connect [40]). In line with those, Hanelt et al. [32] claim that subscription fees are mostly charged for product-related services based on the connection of cars with smartphones. Another way of capturing value is usage-based pricing. So far, this approach was mainly applied in the area of vehicle insurance [44, 49, 38]. However, this type of revenue model is likely to gain relevance once cars are no longer owned as a product but rented, leased, or shared [24]. For services with no or low willingness to pay, the advertising-based revenue model is best suited for indirect monetization, which does not charge users [30]. Three further revenue models are mentioned in the studies on business model patterns for the connected car, namely add-on, freemium, and razor \& blade [16, 17]. They have the composition of different pricing mechanisms (e.g., free basic version, chargeable premium version) in common. 
(2) Selling Data: Besides selling services, OEMs can also take the straightforward approach to monetize data by selling it via third-party platforms (e.g., Caruso). These marketplaces, however, are highly dependent on the OEMs' data supply, which leads to the latter having control over the pricing. From OEMs' standpoint, cooperating with marketplaces makes sense in order to profit from additional data sales, but only to the extent that this does not affect their market shares [14].

Cost Structure: In contrast to traditional business models, the main costs in data-driven services shift from $R \& D$, production, sales, and marketing to service design, technology acquisition costs, and knowledge management activities [36]. Consequently, automotive companies should carry out a substantial investment in appropriate measures for adaption to the digital transformation to increase their profits, productivity, and competitiveness [53, 37]. However, Llopis-Albert et al. [37] observed that companies are somehow reluctant to invest substantial capital in developing new services because there is no immediate payoff, which entails capital risk, and the return on investment is uncertain. Their statement contrasts with the findings of De [30], who claims that the recurring revenues from connected services will surpass the mainly one-time costs. $\mathrm{He}$ adds that the increasing revenue from these services reduces OEMs' costs and leads to positive lifetime value for customers [30]. Further examples of cost reduction through digitalization include digital co-creation in the design process [24], or the transformation of existing products and services into digital variants [17].

\section{Discussion and Conclusion}

\subsection{Implications and Limitations}

Theoretical Implications: In terms of theoretical implications, our work contributes to the body of knowledge on connected cars and related DDBMs, exploring a research area still in its infancy $[2,38]$. We argue that studying this topic is a highly worthwhile endeavor, as we expect the number of connected cars, their collected data, and customers' willingness to pay for connected services are proliferating. Thereby, our main contribution is a literature review extending the business model framework by Al-Debei and Avison [19] and transferring it to the context of DDBMs and connected cars. We propose that scholars publishing novel DDBM research in the connected car domain benchmark their work against our categorization to classify it in the existing body of literature and identify further research gaps. We also provide the following theoretical implications:
(1) Investigate Privacy \& Ethics: As the amount of car data collected grows steadily, privacy and ethics are considered vital by scholars, drivers, and businesses. Particularly with behavioral data (e.g., speeding), companies must earn customers' trust by only using driving data to improve the end-user experience and not for other purposes (e.g., tracking speeders for the police) [2]. Accordingly, raising society's awareness of what kind of data vehicles generate and to whom it is potentially transmitted is essential and may be encouraged by research [8]. Moreover, the question arises: Who ultimately owns the data and how can it be protected [24]? Regarding ethical implications, connected car services (e.g., usage-based insurance) may provide significant societal benefits by improving driving styles, thereby reducing congestion, accident risks, and fuel consumption [38, 33].

(2) Integrate Empirical Data: As this literature review has exposed, a large share of work on connected car business models builds on empirical data such as white papers, websites, and press releases. For such studies, we observe that the website crunchbase.com is increasingly used as a viable resource, providing data on connected car startups (e.g., founding year, funding rounds, and a description). Likely, this will also be the case for much of the upcoming research. Future work could go beyond the information provided on crunchbase.com and investigate certain startups in-depth regarding customer benefits, data access, or pricing strategies. Consequently, the question remains: How to combine the theoretical knowledge from our literature review with empirical findings from practice?

Practical Implications: Concerning the critical task of monetizing car data, our findings have several practical implications for automotive executives. Specifically, our literature review provides a detailed understanding of leveraging car data to enable innovative services. We propose four implications to unlock the full potential of car data successfully:

(1) Incentivize Data Sharing: For connected car business models, customers' willingness to share data is considered as crucial. We identified several incentives and measures to reduce privacy concerns to overcome end-customers' reservations about allowing their data to be used. First, connected car service providers need to increase transparency about what, how, and why data is used $[4,8,15]$ to increase trust in them [49]. Second, they should offer services based on anonymized data [49] to encourage sharing of personalized data. Third, it is crucial to demonstrate benefits from connected services $[4,8,39,26]$ with a clear value proposition (e.g., positive environmental impact). Last, monetary incentives and savings in 
connected service use could encourage data sharing [26, 49]. Nevertheless, it remains unclear how customers perceive these incentives and whether they are willing to share data without monetary incentives.

(2) Enhance Customer-Centricity: Creating customer-specific services is an arduous task, requiring automotive industry players to understand rapidly changing customer needs comprehensively [43, 28]. Scholars have noted the importance of two imperatives that may help enhance customer-centricity. First, establishing customer co-creation, where users are treated like active resource integrators and essential value creators. Here, customers should be involved in the product design process in order to satisfy their needs [32] and, more importantly, be involved for data acquisition purposes [48, 39, 33] to realize DDBMs. Second, leveraging user experience by combining digital service experience with emotions of physical cars to increase customer satisfaction and incentivize data collection. This might be accomplished through seamless user experience [43], personalization [15, 27], or digital technologies (e.g., augmented reality) [53]. Both imperatives raise the question: How to establish customer co-creation in a collaborative environment to create service experiences that customers appreciate?

(3) Engage External Collaboration: Several reports have shown that in the rapidly evolving automotive environment with rising competitor pressure [43, 28, 40], companies should consider which aspects of data monetization they want to tackle internally and which are best addressed through external collaboration. Hence, companies need to open up to strategic partnerships to operate complex data-based services [44, $31,36]$ to acquire external knowledge and competencies (e.g., big data analytics) $[48,51,26]$, access new revenue sources (e.g., data sales) [30, 51, 45], and profit form network effects [10]. In particular, the future role of OEMs is changing drastically. By now, they must place the same importance on their ecosystem partners as they do on car owners [30]. The question for legacy OEMs remains: How to execute the required transition from monopolist to orchestrator?

(4) Build Internal Capabilities: To exploit the value of car data fully, companies need to build strong internal capabilities alongside an ecosystem of strategic partners. Our results suggest that incumbent firms could do this by embracing the following implications. First, they need to integrate digital technological competencies by attracting new talents with the right skills and an agile mindset [43, 31, 32], instead of filling prescribed jobs again. Second, it is crucial to implement startup mentality [43] by structuring the connected car business as a separate entity. Thereby, the question of which approach (e.g., innovation hubs [51] or internal startups [26]) is most appropriate is left open. However, practice has witnessed that agile teams should be located outside the current line organization to create an innovation culture and enable DDBMs at tech company speed [43].

Limitations: As any study, ours is subject to limitations. While a systematic review should ensure a relatively complete count of the relevant literature [20], it is unlikely that we have identified every article that is potentially relevant to our objective. Moreover, DDBMs and connected cars are two fast-evolving research disciplines. Therefore, this review must be considered as a quick blink in time. Furthermore, our work focuses on connectivity as a megatrend disrupting the mobility industry and excludes all research that specifically addresses other technological drivers such as electric, autonomous, and shared mobility.

\subsection{Agenda for Future Research}

There are several research opportunities for future investigations. First, there is no denying that incumbents are still struggling when it comes to monetizing car data. It is surprising that research to date has predominantly focused on OEMs and other traditional players in the supply chain have been largely overlooked. For example, there are several studies that focus on specific car manufacturers, namely Volvo [51, 23, 45], Audi [40], and BMW [53, 36], while the digital transformation of automotive suppliers has not yet been analyzed. It is particularly important to address supplier challenges and explore alternative distribution channels, new data platforms, and novel DDBM. In fact, suppliers currently have no or only limited access to end-customers and their vehicle data [14]. However, this will change with the growth of online channels and data marketplaces. Second, since no theoretical evaluation of car data privacy has been done in the existing literature, theory building is essential. From a theoretical building perspective, an appropriate starting point would be the privacy calculus model [56], which proposes an individual's intention to disclose information based on a risk-benefit analysis. Accordingly, one could apply the model to investigate how people preserve their privacy in car data-enabled business models and test, adapt and extend corresponding theories. Third, connected cars' digital services have hardly been investigated in terms of their benefits for businesses, consumers, or society. In addition, most studies are limited to merely naming, listing, or explaining various services. Accordingly, studies designing services and associated DDBMs for connected cars are needed. These could be carried out, considering actual vehicle 
data (e.g., Caruso). Last, revenue models and pricing strategies are rather unexplored outside the traditional automotive business models and are at best mentioned or explained. Investigating how customers would like to pay for connected services is vital to shaping pricing and sales models according to customer preferences. Experimental studies may represent a suitable means to investigate these. Another unresearched topic is the direct sale of vehicle data by the OEM. In this context, it is crucial to consider suitable pricing strategies for monetizing vehicle data that are attractive to OEMs, independent service providers, and end-users.

In conclusion, the tremendously growing amount of car data has considerable potential for the provision of DDBMs shaping future mobility. Researchers and practitioners may find this review helpful for better understanding and developing innovative DDBMs for the connected car and use it as a reference for further research endeavors. To conclude, although the monetization potential of car data is immense, it is still at an early stage, leaving the question of how to monetize car data unanswered. We encourage scholars to join us in our search for answers.

\section{References}

[1] T. Häberle, L. Charissis, C. Fehling, J. Nahm, and F. Leymann, "The Connected Car in the Cloud: A Plattform for Prototyping Telematics Services," IEEE Software, vol. 32, no. 6, pp. 11-17, 2015.

[2] C. Kaiser, A. Stocker, A. Festl, G. Lechner, and M. Fellmann, "A research agenda for vehicle information systems," in ECIS 2018 Proceedings, pp. 1-12, 2018.

[3] B. J. Hood, O. Hoda, and R. Robinson, "Monetizing data in the age of connected vehicles," Deloitte Insights, pp. 1-7, 2019.

[4] A. M. Soley, J. E. Siegel, D. Suo, and S. E. Sarma, "Value in vehicles: economic assessment of automotive data," Digital Policy, Regulation and Governance, vol. 20, no. 6 , pp. 513-527, 2018.

[5] M. Winkler, R. Mehl, M. Matthies, S. Monske, C. Kolhas, N. Kiefer, P. Purrucker, and R. Gräber, "Monetizing Vehicle Data: How to fulfill the promise," Capgemini, pp. 1-20, 2020.

[6] B. Heid, C. Huth, G. Wu, and S. Kempf, "Ready for inspection: The automotive aftermarket in 2030.," McKinsey \& Company, pp. 1-52, 2018.

[7] C. Martens and T. Schneiderbauer, "Unlocking the full life-cycle value from connected-car data," McKinsey \& Company, pp. 1-15, 2021.

[8] A. Stocker, C. Kaiser, and M. Fellmann, "Quantified Vehicles: Novel Services for Vehicle Lifecycle Data,' Business and Information Systems Engineering, vol. 59, no. 2, pp. 125-130, 2017.

[9] P. Parvinen, E. Pöyry, R. Gustafsson, M. Laitila, and M. Rossi, "Advancing data monetization and the creation of data-based business models," Communications of the
Association for Information Systems, vol. 47, no. 1, pp. 25-49, 2020.

[10] M. Bosler, C. Jud, and G. Herzwurm, "Platforms and Ecosystems for Connected Car Services," in Proceedings of the 9th International Workshop on Software Ecosystems, pp. 16-27, 2017.

[11] A. Athanasopoulou, M. de Reuver, S. Nikou, and H. Bouwman, "What technology enabled services impact business models in the automotive industry? An exploratory study," Futures, vol. 109, no. 1, pp. 73-83, 2019.

[12] C. Kaiser, A. Stocker, and M. Fellmann, "Understanding data-driven service ecosystems in the automotive domain," in AMCIS 2019 Proceedings, pp. 1-10, 2019.

[13] F. Zhao, H. Tan, and Z. Liu, "Analysis of the Business Models of the Intelligent and Connected Vehicle Industry," in MATEC Web of Conferences, pp. 1-5, 2020.

[14] B. Martens and F. Mueller-Langer, "Access To Digital Car Data and Competition in Aftermarket Maintenance Services," Journal of Competition Law Economics, vol. 16, no. 1, pp. 116-141, 2020.

[15] R. Coppola and M. Morisio, "Connected car: Technologies, issues, future trends," ACM Computing Surveys, vol. 49, no. 3, pp. 1-36, 2016.

[16] M. Mikusz, C. Jud, and T. Schäfer, "Business Model Patterns for the Connected Car and the Example of Data Orchestrator," in ICSOB 2015 Proceedings, pp. 5-6, 2015.

[17] M. Mikusz, T. Schafer, T. Taraba, and C. Jud, "Transforming the connected car into a business model innovation," in IEEE CBI 2017 Proceedings, pp. 247-256, 2017.

[18] C. Kaiser, A. Festl, G. Pucher, M. Fellmann, and A. Stocker, "Digital Services Based on Vehicle Usage Data: The Underlying Vehicle Data Value Chain," in 15th International Conference on Web Information Systems and Technologies, pp. 22-43, 2020.

[19] M. M. Al-Debei and D. Avison, "Developing a unified framework of the business model concept," European Journal of Information Systems, vol. 19, no. 3, pp. 359-376, 2010.

[20] J. Webster and R. T. Watson, "Analyzing the Past to Prepare for the Future: Writing a Literature Review," MIS Quarterly, vol. 26, no. 2, pp. xiii - xxiii, 2002.

[21] J. Vom Brocke, A. Simons, B. Niehaves, K. Riemer, R. Plattfaut, and A. Cleven, "Reconstructing the giant: On the importance of rigour in documenting the literature search process," in ECIS 2009 Proceedings, pp. 2206-2217, 2009.

[22] G. Paré, M. C. Trudel, M. Jaana, and S. Kitsiou, "Synthesizing information systems knowledge: A typology of literature reviews," Information and Management, vol. 52, no. 2, pp. 183-199, 2015.

[23] P. Andersson and L.-G. Mattsson, "Service innovations enabled by the "internet of things"," IMP Journal, vol. 9, no. 1, pp. 85-106, 2015.

[24] A. Athanasopoulou, H. Bouwman, F. Nikayin, and M. de Reuver, "The disruptive impact of digitalization on the automotive ecosystem: A research agenda on business models, platforms and consumer issues," in BLED 2016 Proceedings, pp. 597-604, 2016.

[25] I. Bauer, L. Zavolokina, and G. Schwabe, "Is there a market for trusted car data?," Electronic Markets, vol. 30, no. 2, pp. 211-225, 2020. 
[26] N. Brandt and F. Ahlemann, "How Do You Drive? Analyzing Vehicle Sensor Data In Product Lifecycle Management Systems," in ECIS 2020 Proceedings, pp. 1-15, 2020.

[27] R. Bregant, C. Jandl, P. Brune, and H. Gewald, "How to manage the segment-of-one? A framework to reduce customer complexity," in ECIS 2017 Proceedings, pp. 98-113, 2017.

[28] S. Chanias and T. Hess, "Understanding digital transformation strategy formation: Insights from Europe's automotive industry," in PACIS 2016 Proceedings, pp. 1-15, 2016.

[29] P. Conradi, D. Gräfe, T. Lüders, M. Wahl, and A. Weide, "A secure vehicle-based telematics environment used for enhanced smartphone communication," AmE 2016 Automotive meets Electronics, pp. 105-110, 2016.

[30] S. De, "Next-Gen Business Models for the Automotive Industry for Connected Cars and Services," SAE Technical Papers, pp. 1-14, 2018.

[31] M. Grieger and A. Ludwig, "On the move towards customer-centric business models in the automotive industry - a conceptual reference framework of shared automotive service systems," Electronic Markets, vol. 29, no. 3, pp. 473-500, 2019.

[32] A. Hanelt, E. Piccinini, R. W. Gregory, B. Hildebrandt, and M. Lutz, "Digital Transformation of Primarily Physical Industries - Exploring the Impact of Digital Trends on Business Models of Automobile Manufacturers," in WI 2015 Proceedings, pp. 1313-1327, 2015.

[33] C. Kaiser, A. Stocker, G. Viscusi, and P. Moertl, "Quantified Cars: An exploration of the position of ICT start-ups vs. car manufacturers towards digital car services and sustainable business models," in 2nd International Conference on New Business Models, pp. 1-16, 2017.

[34] C. Kaiser, A. Stocker, and G. Viscusi, "Digital vehicle ecosystems and new business models: An overview of digitalization perspectives," in $i$-know 2017 Proceedings, pp. 1-8, 2017.

[35] C. Kaiser, A. Stocker, G. Viscusi, M. Fellmann, and A. Richter, "Conceptualising value creation in data-driven services: The case of vehicle data," International Journal of Information Management, vol. 59, no. 1, pp. 1-15, 2021.

[36] P. K. Kukkamalla, A. Bikfalvi, and A. Arbussa, "The new BMW: business model innovation transforms an automotive leader," Journal of Business Strategy, vol. 1, no. 1, pp. 1-10, 2020.

[37] C. Llopis-Albert, F. Rubio, and F. Valero, "Impact of digital transformation on the automotive industry," Technological Forecasting Social Change, vol. 162, no. 1, pp. 1-9, 2021.

[38] M. Marabelli, S. Hansen, S. Newell, and C. Frigerio, "The light and dark side of the black box: Sensor-based technology in the automotive industry," Communications of the Association for Information Systems, vol. 40, no. 1, pp. 351-374, 2017.

[39] M. Mikusz and T. Herter, "How do consumers evaluate value propositions of connected car services?," in AMCIS 2016 Proceedings, pp. 1-10, 2016.

[40] M. Mocker and N. Fonstad, "Driving Digitization at Audi," in ICIS 2017 Proceedings, pp. 1-15, 2017.
[41] F. Nischak and A. Hanelt, "Ecosystem change in the era of digital innovation - A longitudinal analysis and visualization of the automotive ecosystem," in ICIS 2019 Proceedings, pp. 1-17, 2019.

[42] J. Peng, N. Liu, H. Zhao, and M. Yu, "Usage-based insurance system based on carrier-cloud-client," in 2015 10th International Conference on Communications and Networking in China, pp. 579-584, 2015.

[43] E. Piccinini, A. Hanelt, R. W. Gregory, and L. M. Kolbe, "Transforming industrial business: The impact of digital transformation on automotive organizations," in ICIS 2015 Proceedings, pp. 1-20, 2015.

[44] F. Pütz, F. Murphy, M. Mullins, and L. O’Malley, "Connected automated vehicles and insurance: Analysing future market-structure from a business ecosystem perspective," Technology in Society, vol. 59, no. 1, pp. 1-9, 2019.

[45] I. Rahman and R. Tadayoni, "Digital Transformation of Automobiles - From product to service," in 11th CMI International Conference 2018, pp. 7-13, 2018.

[46] G. Remane, B. Hildebrandt, A. Hanelt, and L. M. Kolbe, "Changes in Digital Business Model Types A Longitudinal Study of Technology Startups from the Mobility Sector," in AMCIS 2016 Proceedings, pp. 1-10, 2016.

[47] G. Remane, B. Hildebrandt, A. Hanelt, and L. M. Kolbe, "Discovering new digital business model types - A study of technology startups from the mobility sector," in PACIS 2016 Proceedings, pp. 1-16, 2016.

[48] T. Riasanow, G. Galic, and M. Böhm, "Digital transformation in the automotive industry: Towards a generic value network," in ECIS 2017 Proceedings, pp. 3191-3201, 2017.

[49] C. Roth, S. Aringer, J. Petersen, and M. Nitschke, "Are Sensor-Based Business Models a Threat to Privacy? The Case of Pay-How-You-Drive Insurance Models," in International Conference on Trust and Privacy in Digital Business, pp. 75-85, 2020.

[50] F. Svahn, R. Lindgren, and L. Mathiassen, "Applying options thinking to shape generativity in digital innovation: An action research into connected cars," in HICSS 2015 Proceedings, pp. 4141-4150, 2015.

[51] F. Svahn, L. Mathiassen, and R. Lindgren, "Embracing Digital Innovation in Incumbent Firms: How Volvo Cars Managed Competing Concerns," MIS Quarterly, vol. 41, no. 1, pp. 239-253, 2017.

[52] M. Swan, "Connected car: Quantified self becomes quantified car," Journal of Sensor and Actuator Networks, vol. 4, no. 1, pp. 2-29, 2015.

[53] J. Tian, A. Chin, and M. Karg, "Digital Services in the Automotive Industry," IT Professional, vol. 18, no. 1, pp. 4-6, 2016.

[54] S. Toglaw, M. Aloqaily, and A. A. Alkheir, "Connected, autonomous and electric vehicles: The optimum value for a successful business model," in 5th International Conference on Internet of Things: Systems, Management and Security, pp. 303-308, 2018.

[55] E. Uhlemann, "The battle of technologies or the battle of business models? [connected vehicles]," IEEE Vehicular Technology Magazine, vol. 13, no. 1, pp. 14-18, 2018.

[56] T. Dinev and P. Hart, "An Extended Privacy Calculus Model for E-Commerce Transactions," Information Systems Research, vol. 17, no. 1, pp. 61-80, 2006. 